MARIELe ANDRADE do NASCIMENTo

\title{
Associação entre polimorfismos genéticos em RANK, RANKL e OPG com alterações nas dimensões craniofaciais
}

Tese apresentada à Faculdade de Odontologia de Ribeirão Preto da Universidade de São Paulo, para obtenção do título de Doutor em Ciências.

Programa: Odontopediatria

Área de Concentração: Odontopediatria

Orientador: Prof. Dr. Paulo Nelson Filho

Coorientadora: Profa. Dra. Érika Calvano Kuchler 


\section{AutorizaÇÃo Para RePROdUÇÃo}

Autorizo a reprodução e divulgação total ou parcial deste trabalho, por qualquer meio convencional ou eletrônico, para fins de estudo e pesquisa, desde que citada a fonte.

MARIELE ANDRADE do NASCIMENTO

FICHA CATALOGRÁFICA

Nascimento, Mariele Andrade do

Associação entre polimorfismos genéticos em RANK, RANKL e OPG com alterações nas dimensões craniofaciais. Ribeirão Preto, 2017.

85p. : il. ; $30 \mathrm{~cm}$

Tese apresentada à Faculdade de Odontologia de Ribeirão Preto da Universidade de São Paulo, para obtenção do título de Doutor em Ciências. Programa de Pós-Graduação em Odontopediatria. Área de Concentração: Odontopediatria.

Orientador: Prof. Dr. Paulo Nelson Filho.

Coorientadora: Profa. Dra. Érika Calvano Kuchler

1. Face. 2 . Polimorfismo genético 3 . Cefalometria 
FolHa de APROVAÇÃo

Nascimento, MA. Associação entre polimorfismos genéticos em RANK, RANKL e OPG com alterações nas dimensões craniofaciais.

Tese apresentada à Faculdade de Odontologia de Ribeirão Preto da Universidade de São Paulo, para obtenção do título de Doutor em Ciências.

Programa: Odontopediatria.

Área de Concentração: Odontopediatria.

Data da defesa:

-

\section{BANCA EXAMI NADORA}

Prof.(a). Dr.(a):

J ulgamento: Assinatura:

Prof.(a). Dr.(a):

J ulgamento: Assinatura:

Prof.(a). Dr.(a):

J ulgamento: Assinatura:

Prof.(a). Dr.(a):

J ulgamento: Assinatura:

Prof.(a). Dr.(a):

J ulgamento: Assinatura: 

Nascimento: 29 de Março de 1989, Colorado, PR

Filiação: Ermozilio do Nascimento e Maria Eunice Andrade

2007-2010: Curso de Graduação em Odontologia

Centro Universitário de Maringá-CESUMAR - PR

2012-2014: Mestrado em Odontologia

Área de concentração: Odontologia Integrada

Universidade Estadual de Maringá- UEM- PR

2013-2016: Especialização em Ortodontia

Universidade Estadual de Maringá - UEM- PR 


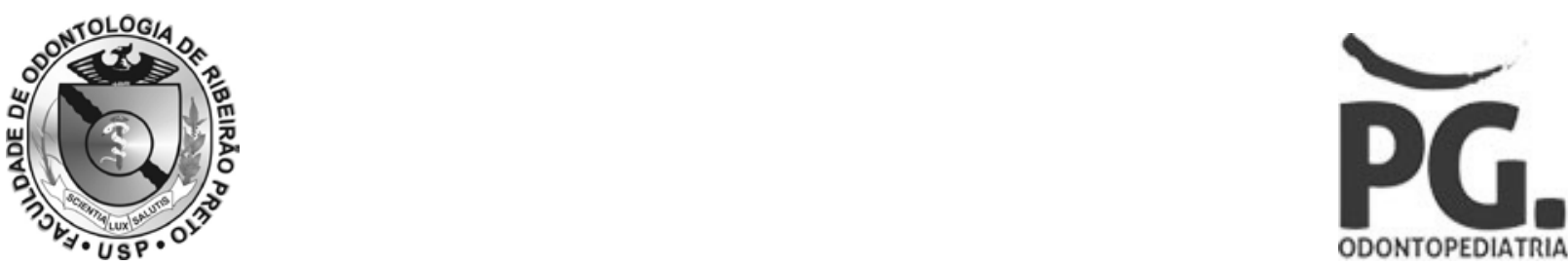

Trabalho desenvolvido nas Clínicas I, II e III e no laboratório de Biologia Molecular e Cultura de Células - Departamento de Clínica Infantil - Faculdade de Odontologia de Ribeirão Preto - USP. Auxílio Regular FAPESP e bolsa CAPES. 

Dedicatória 

Dedico este trabalho primeiramente a Deus, aos meus pais, aos meus irmãos e ao meu esposo (hoje pai do meu filho), pelo amor e compressão a mim dedicados.

A Deus, por ser exemplo de fidelidade, luz, dignidade, fortaleza e amor intenso e verdadeiro.

À famillia, por nunca me abandonar, em nenhum momento; um exemplo de amor intenso e fidelidade.

Aos meus amigos que sempre, de alguma forma, colaboraram e incentivaram.

Consagre ao Senhor tudo o que você faz, e os seus planos serão bem-sucedidos.

Provérbios 16:3 



\section{Agradecimentos}





\section{Professor Paulo Nelson, meu orientador,}

Tenho muita admiração pelo seu imenso conhecimento e dedicação. Pessoa organizada, inteligente e bonita por dentro e por fora. Muitas vezes tive medo de não acompanhar tanta informação que tem a oferecer e, com prazer, didática, carinho e método transmite. Pessoa agraciada pelo dom de ensinar, pesquisar, acolher e ter ideias. Agradeço imensamente por tudo que me ofereceu.

\section{Professora Erika, minha coorientadora,}

Pessoa tão fácil e tão difícil. "Fácil" porque sempre resolve tudo da melhor maneira, com seu jeito descomplicado e coração grande. Atua como mãe que,pelo tamanho do coração, faz tudo pelo filho (no meu caso, filha adotiva). Irmã pela idade cronológica. "Difícil" porque não sei se mensura o tamanho da gratidão que tenho. Que Deus sempre a recompense da melhor maneira.

Hoje, a sensação presente em minha vida é de intensa gratidão, a tudo e a todos que sempre colaboraram de alguma forma para que os acontecimentos fluíssem sempre. Quanta energia positiva. Cheguei em Ribeirão Preto e já tinha uma casa, com pessoas que sempre me acolheram como irmã: Gabriela Santin, Marilia e Aline; filha também, não é Danizinha. Quantos desafios, incluindo distâncias físicas, ônibus e a saúde do meu pai que, mesmo não sendo tão integra, Deus permitiu até hoje estar presente na minha vida.

São tantas pessoas que Deus colocou na minha vida... 
À Faculdade de Odontologia de Ribeirão Preto da Universidade de São Paulo, na pessoa da atual diretora Profa. Dra. Léa Assed Bezerra da Silva e do Vice-Diretor Prof. Dr. Arthur Belém Novàes Júnior.

À Coordenação do Curso de Pós-Graduação em Odontopediatria da Faculdade de Odontologia de Ribeirão Preto da Universidade de São Paulo, na pessoa da Coordenadora Profa. Dra. Raquel Assed Bezerra Segato e da Vice-Coordenadora Profa. Dra. Léa Assed Bezerra da Silva.

Aos Professores da Disciplina de Odontopediatria da Faculdade de Odontologia de Ribeirão Preto da Universidade de São Paulo, Profa. Dra. Léa Assed Bezerra da Silva, Prof. Dr. Paulo Nelson Filho, Profa. Dra. Alexandra Mussolino de Queiroz,Profa. Dra.Raquel Assed Bezerra Segato, Profa. Dra. Aldevina Campos de Freitas, Profa. Dra. Maria Cristina Borsatto, Profa. Dra Andiara De Rossi Daldegan, Prof. Dr. Fabrício Kitazono de Carvalho e Profa. Dra. Kranya Victória Díaz Serrano, pela agradável convivência, pelas conversas atenciosas e pelos conhecimentos transmitidos.

Aos Professores da Disciplina de Ortodontia da Faculdade de Odontologia de Ribeirão Preto da Universidade de São Paulo, Prof. Dr. Adĩlson Thomazinho, Prof. Dr. Fábio Lourenço Romano, Prof. Dr. Josê Tarcísio Lima Ferreira, Profa. Dra. Maria Bernadete Sasso Stuani e Profa. Dra. Mírian Aiko Nakane Matsumoto, pelos conhecimentos transmitidos e disponibilidade em todos os momentos.

Agradeço aos professores e amigos da Especialização em Maringá, pelo carinho e ajuda, quando eu não conseguiria estar presente. 
Micheli, secretâria da Pós-Graduação, sempre com muita paciência para responder minhas dūvidas, conversar e explicar cada detalhe.

Filó e Matheus, secretários sempre presentes e dedicados a ajudar.

Nilza, uma amiga, além de técnica de laboratório. No começo quase todos tinham alguma atividade no laboratório e eu não, mas depois morei lá por uma temporada. Tudo parecia tão novo e diferente. Depois tudo passou a ser tão familiar, como tudo na nossa vida, de maneira agradável.

Professora Mirian, você foi muito importante e nunca mediu esforços para colaborar. Conversamos sempre com muita naturalidade. Que Deus preserve sempre essa sua bondade.

Professor Fábio, sempre facilitando a integração com a Ortodontia. Pessoa dedicada e abençoada.

São tantas pessoas abençoadas...Priscila, Karla, Driely, Patricia, Elaine, Larissa, Silvana, Mariana, Marina, Leonardo, Késsia, Marïlia, Arthur, pessoal da especialização.

Marjorie, pessoa que chegou e parecia que iá conhecia há anos. Sempre disposta a ajudar e aprender. Amiga que coloriu ainda mais os dias em Ribeirão Preto.

Raquel Morelli, pessoa cheia de paz. Parceira, sempre presente, disponível e alegre.

Karla Carpio, me acolheu no seu lar com todo carinho e conforto, sempre disposta a ajudar.

A todos os pacientes, que participaram da Pesquisa. 
À equipe do programa Dolphin, em especial ao Rogério, pela atenção e trabal lho com seriedade.

À secretāria do Curso de Especialização em Ortodontia, Rosemary, pela amizade, compreensão e carinho.

Aos funcionários da Clínica I da Faculdade de Odontologia de Ribeirão Preto da Universidade de São Paulo, José Aparecido Neves do Nascimento, Vera do Nascimento Scandelai e Karina Dadalt Quaglio, obrigada pela prontidão em me atender, pela alegre convivência, pelo apoio e carinho.

À CAPES (Coordenação de Aperfeiçoamento de Pessoal de Nível Superior), pela concessão da bolsa.

À Fapesp (Fundação de Apoio à Pesquisa do Estado de São Paulo) pelo auxîlio financeiro concedido.

Agora, pois, permanecem a fé, a esperança $e$ o amor, estes três, mas o maior destes éo amor. 
Sumário 



\section{RESUMO}

\section{ABSTRACT}

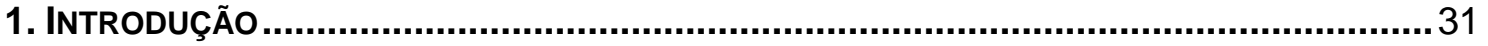

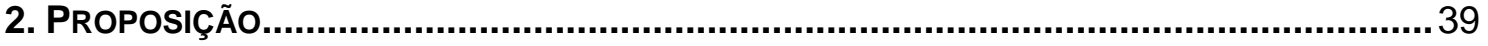

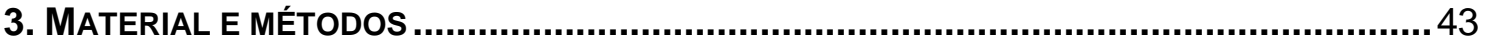

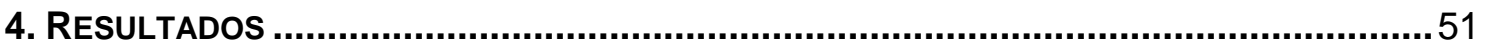

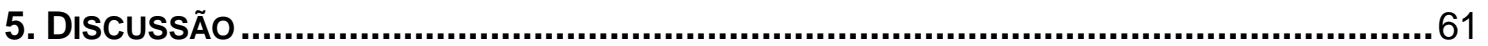

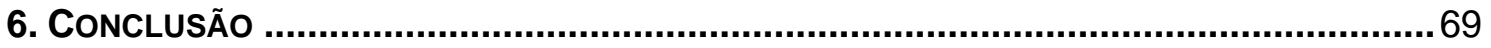

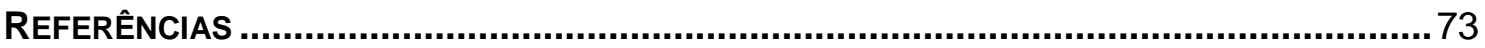

ANEXO 

Resumo 

Nascimento, MA. Associação entre polimorfismos genéticos em RANK, RANKL e OPG com alterações nas dimensões craniofaciais. Ribeirão Preto, 2017. 85p. Tese [Doutorado]. Faculdade de Odontologia de Ribeirão Preto, Universidade de São Paulo.

\section{RESUMO}

O objetivo do presente estudo foi avaliar, em humanos, a associação entre polimorfismos genéticos no sistema RANK/RANKL/OPG com as dimensões craniofaciais. Foram incluídos neste estudo um total de 100 indivíduos caucasianos brasileiros não relacionados. O DNA foi extraído da saliva de cada um dos participantes e os polimorfismos rs3826620, rs9594738 e rs2073618 em RANK, RANKL e OPG, respectivamente, foram analisados por PCR em tempo real. Para avaliação das dimensões craniofaciais foram avaliadas três medidas angulares (SNA, SNB e ANB) e quatro medidas lineares (Co-Gn, Go-Pg, Co-Go e PTM-A), obtidas de traçados cefalométricos. Para avaliar a distribuição dos genótipos de acordo com os padrões esqueléticos faciais (Classe I, Classe II e Classe III) foi utilizado o teste do qui-quadrado. Para comparar as médias das dimensões maxilares e mandibulares de acordo com os genótipos utilizou-se o teste de KruskalWallis, com o pós-teste de Dunn para comparações múltiplas, ou ANOVA com pósteste de Tukey. Foi utilizada a análise de regressão linear multivariada para ajustar a possível influência da idade e do gênero em cada medida. O equilíbrio de HardyWeinberg foi avaliado utilizando o teste do qui-quadrado para cada polimorfismo. $O$ nível de significância adotado para todas as análises foi $5 \%$. Os resultados obtidos evidenciaram que não houve associação estatisticamente significante entre a distribuição genotípica de RANK, RANKL e OPG com as médias dos ângulos SNA e SNB, nem com a distribuição fenotípica (padrão esquelético Classe I, II ou III) $(p>0,05)$. Observou-se diferença estatisticamente significante entre a distribuição das medidas do comprimento da base mandibular, de acordo com os genótipos de RANK, onde o genótipo GG apresentou maior medida de Go-Pg $(p=0,039)$. Na análise multivariada, observou-se associação significante para os polimorfismos em RANK e medidas mandibulares (Go-Pg e Co-Gn) $(p<0,05)$. A medida da maxila não foi associada a nenhum polimorfismo. Conclui-se que houve associação entre o polimorfismo genético rs3826620 em RANK com maiores dimensões mandibulares, onde o comprimento da mandíbula (Co-Gn) e o comprimento da base da mandíbula (Go-Pg) estavam aumentados.

Palavras-chave: face, polimorfismo genético, cefalometria. 

Abstract 

Nascimento, MA. Association between genetic polymorphisms in RANK, RANKL and OPG with changes in craniofacial dimensions. Ribeirão Preto, 2017.85p.Thesis - School of Dentistry of Ribeirão Preto University of São Paulo.

\section{ABstract}

The objective of the present study was to evaluate, in humans, the association between genetic polymorphisms in the RANK/ RANKL/OPG system with alterations in craniofacial dimensions. A total of 100 unrelated Brazilian Caucasians were included in this study. DNA was extracted from the saliva of each of the participants and the polymorphisms rs3826620, rs9594738 and rs2073618 in RANK, RANKL and OPG, respectively, were analyzed by real-time PCR. To evaluate the craniofacial dimensions, three angular measurements (SNA, SNB and ANB) and four linear measurements (CoGn, Go-Pg, Co-Go and PTM-A) were obtained from cephalometric tracings. To compare the difference between the means of the linear and angular measurements according to the genotype, Kruskal-Wallis followed by Dunn post test or ANOVA followed by the Tukey post test was used. Linear regression analysis was also used to adjust the possible influence of age and gender on each linear maxillary and mandibular measure. The Hardy-Weinberg equilibrium was also evaluated using the chi-square test within each polymorphism. The level of significance was $5 \%$. The results demonstrated that there were no statistically significant association between the genotypic distribution of RANK, RANKL, OPG, and the angules SNA, SNB and according to the phenotypic distribution (Class I, Class II or Class III of skeletal pattern) ( $p>0.05$ ). A statistically significant difference was observed between the distribution of mandibular base length measurements according to the RANK genotypes, where the GG genotype showed a higher Go-Pg measurement $(p=0.039)$. In the multivariate analysis, a statistically significant association was found for RANK and mandibular (Go-Pg and Co-Gn) polymorphisms $(p<0.05)$. Measurement of the maxilla was not associated with any polymorphism. It was concluded that there was an association between genetic polymorphism rs3826620 in RANK with a greater mandibular dimension, in which the length of the mandible (Co-Gn) and the length of the base of the mandible (Go-Pg) were increased.

Keywords: face, genetic polymorphism, cephalometry 

1. Introdução 



\section{INTRODUÇÃO}

O esqueleto craniofacial desempenha várias funções, incluindo a acomodação do cérebro e dos órgãos sensoriais. Atua, também, como base para os músculos da mastigação, o que permite o movimento mandibular, possibilitando a realização de funções como mastigação, respiração, alimentação e fala (Madeira, 2012).

As estruturas do esqueleto craniofacial são desenvolvidas a partir de processos moleculares complexos, envolvendo interações teciduais e celulares que regulam o crescimento e o desenvolvimento da maxila e da mandíbula (Kouskoura et al., 2011; Nieminen et al., 2011). O desenvolvimento dos ossos maxilares e mandibulares, assim como o desenvolvimento dos músculos a eles unidos, possui uma relação direta com os padrões esqueléticos faciais (Huh et al., 2013; Bayram et al., 2014). Por outro lado, as discrepâncias no crescimento e no desenvolvimento do esqueleto craniofacial são consideradas alterações do desenvolvimento, as quais podem influenciar a posição e orientação da maxila, da mandíbula, dos músculos da mastigação e dos dentes, conduzindo a alterações nas dimensões craniofaciais (Proffit et al., 2012).

Estudo com famílias e com gêmeos sugerem que a etiologia das dimensões craniofaciais é poligênica e de natureza multifatorial, isto é, diversos fatores genéticos e ambientais desempenham um papel importante. Cabe ressaltar que um modelo poligênico implica na atuação de diversos genes com pequenos efeitos aditivos (Mossey, 1999).

Nas últimas duas décadas, alguns loci candidatos, como 1p22.1, 1p22.2, 1p36, 3q26.2, 5p13-p12, 6q25, 11q22.2-q22.3, 12q23, 12q13.13 e 19p13.2; e alguns genes candidatos, como MATRILIN-1, COL2A1, GHR, PAZ5, ABC A4, ARHGAP29, SNAI3, MYO1H, TWIST1, PAX7, LTBP2, SHH, BMP3, ANXA2, FLNB, ADMTSI, ARGAP21, HOXA2, P561T eC422F, foram associados com a etiologia das alterações dimensionais da mandíbula (Liu et al., 2012; Adhikari et al., 2016), principalmente com o prognatismo mandibular (Yamaguchi et al., 2005; FrazierBowers et al., 2009; Sasaki et al., 2009; Li et al., 2010; Jang et al., 2010; Xue et al., 2010; Li et al., 2011; Cruz et al., 2011; Tassopoulou-Fishell et al., 2012; Xue et al., 2014; Ikuno et al., 2014; Da Fontoura et al., 2015; Perillo et al., 2015; Guan et al., 2015). Entretanto, o papel dos genes nas dimensões maxilares e mandibulares é um 
tema pouco explorado na literatura específica (Cakan et al., 2012; Nieminen et al., 2011; Da Fontoura, et al., 2015).

Historicamente, estudos que avaliaram as dimensões craniofaciais em famílias e em grupos de gêmeos forneceram informações importantes sobre o papel da genética nas dimensões da maxila e da mandíbula (Nakasima et al., 1982).

Em um estudo com gêmeos realizado por Lundström, em 1948, observou-se que quando esses eram monozigóticos havia concordância de 68\% em ter máoclusão Classe II. Por outro lado, gêmeos dizigóticos demonstraram uma concordância de apenas 24\%, indicando o papel de mecanismos genéticos na máoclusão de Classe II.

Nakasima et al. (1982) analisaram as variáveis cefalométricas em pais e filhos com má-oclusão de Classe II. As medidas esqueléticas entre pais e filhos foram altamente correlacionadas, com um modo de herança poligênica (Nakasima et al., 1982).

Em 1992, Markovic realizou um estudo com medidas cefalométricas obtidas de 48 pares de gêmeos e de seis grupos de trigêmeos. Dentre os gêmeos monozigóticos, 100\% demonstraram concordância para a má-oclusão classe II divisão dois, enquanto que quase $90 \%$ dos dizigóticos foram discordantes. Estes estudos de hereditariedade previamente realizados são uma forte evidência de que a genética atua como fator etiológico na má-oclusão de Classe II divisão dois.

Com relação à má-oclusão de Classe III, um dos casos mais famosos citados na literatura sobre o papel da hereditariedade nas dimensões craniofaciais é o da família imperial austro-húngara, na qual foi observado um padrão de máoclusão Classe III em diversas gerações da família. Nessa família, o prognatismo mandibular era transmitido em um modelo autossômico dominante (Mossey, 1999). Em 1961, Suzuki realizou um estudo com 243 famílias japonesas, observando um padrão de hereditariedade da má-oclusão de Classe III. Já em 1965, Schulze e Weise também analisaram a concordância da má-oclusão de Classe III em gêmeos monozigóticos e gêmeos dizigóticos, na Alemanha. Os autores observaram que a concordância em gêmeos monozigóticos foi seis vezes maior que nos gêmeos dizigóticos, corroborando também a possibilidade de um modelo poligênico. Estes estudos de hereditariedade claramente demonstram o papel da genética na etiologia da má-oclusão de Classe III. Além disso, em um estudo avaliando famílias chinesas 
foi observada a transmissibilidade do prognatismo mandibular, bem como regiões gênicas possivelmente associadas a esse fenótipo (Li et al., 2010).

Neste contexto, os avanços na genética humana e na biologia molecular têm conduzido à identificação de novos genes e loci envolvidos com a etiologia da dimensões craniofaciais (Yamaguchi et al., 2005; Frazier-Bowers et al., 2009; Sasaki et al., 2009; Li et al., 2010; Jang et al., 2010; Xue et al., 2010; Li et al., 2011; Cruz et al., 2011; Tassopoulou-Fishell et al., 2012; Liu et al., 2012; Xue et al., 2014; Ikuno et al., 2014; Da Fontoura et al., 2015; Perillo et al., 2015; Guan et al., 2015; Adhikari et al., 2016; Cruz et al., 2017).

Assim, genes como o Tumor Necrosis Factor Receptor Superfamily, Member 11a, NFKB Activator (RANK), Tumor Necrosis Factor Superfamily, Member 11 (RANKL) e Tumor Necrosis Factor Superfamily, Member11b (OPG ou osteoprotegerina), envolvidos no metabolismo ósseo e considerados mediadores da osteoclastogênese, podem estar envolvidos na etiologia das alterações das dimensões craniofaciais (Bayram et al., 2014; Tyagi et al., 2016).

A remodelação óssea é regulada por um processo altamente dinâmico envolvendo os osteoblastos, formadores de tecido ósseo, e os osteoclastos, que reabsorvem o tecido ósseo. A coordenação entre osteoclastos e osteoblastos é fundamental para a remodelação óssea fisiológica. A osteoclastogênese também é conhecida por ser de grande importância durante o desenvolvimento esquelético na infância e na manutenção do esqueleto na fase adulta (Tyagiet al., 2016). O osso remodela-se continuamente para se adaptar às influências do crescimento e às alterações nas cargas mecânicas, mantendo a homeostase mineral e regulando o ambiente da medula óssea. No esqueleto maduro, a remodelação óssea, além de ser uma fonte de cálcio e fosfato sistêmico, é um meio de substituição de osso danificado por osso sadio (Consolaro, 2009; Boyce et al., 2012).

Até há pouco tempo, considerava-se que as células osteoblásticas eram as células dominantes que regulavam a remodelação óssea. No entanto, tornou-se cada vez mais evidente que as células osteoclásticas desempenham papéis importantes na regulação de osteoblastos e de outras células no microambiente ósseo. Os osteoclastos, ativados pela ligação RANK/RANKL, durante a reabsorção óssea liberam fatores de crescimento, incluindo TGF- $\beta$, fatores de crescimento semelhantes à insulina e as proteínas morfogenéticas do osso, que estimulam a diferenciação de osteoblastos e a neoformação (Boyce et al., 2012). 
A tríade molecular composta por RANK/RANL/OPG é descrita como um sistema-chave para controle da diferenciação e da função dos osteoclastos (Kearns et al., 2008), sendo o RANKL necessário para ativação e para diferenciação dessas células, desempenhando um papel importante na reabsorção e remodelação óssea. A osteoprotegerina é um ligante antagônico natural para o RANKL. Portanto, o equilíbrio entre OPG e RANKL regula a diferenciação de osteoclastos (Hofbauer e Heufelder, 2001).

O RANK é um receptor de citocinas transmembranar nos osteoclastos responsável, por meio da união com seu ligante RANKL, pela osteoclastogênese, com transformação dos osteoclastos em osteoclastos ativos. A regulação da remodelação óssea via osteoclastos é uma das funções essenciais, embora não exclusivas, de RANK e RANKL, in vivo (Walsh e Choi, 2014). Por outro lado, a Osteoprotegerina é uma proteína solúvel, cuja estrutura é semelhante à do RANK, 0 que the permite ligar-se ao RANKL e impedir a ligação RANK/RANKL podendo, assim, bloquear o efeito indutor de osteoclastogênese (Ferreira et al., 2015).

Embora os genes que codificam o RANK (Receptor Ativador do Fator Nuclear kappa $\beta$ ), o RANKL(Ligante do Receptor do Fator Nuclear kappa $\beta$ ) e a OPG (osteoprotegerina) não tenham sido previamente investigados no contexto da dimensões craniofaciais, são genes candidatos por estarem envolvidos no metabolismo e no desenvolvimento ósseo.

Paralelamente, outro aspecto relevante que poderia interferir nas dimensões craniofaciais são os polimorfismos genéticos.

Os polimorfismos genéticos são alterações na sequência de pares de bases do DNA. Embora a maioria destas alterações seja funcionalmente neutra, o polimorfismo pode estar relacionado à regulação da expressão do gene ou à função da proteína codificada, ocasionando diferentes comportamentos biológicos e influenciando a susceptibilidade a doenças (Ye, 2000).

O tipo mais comum de polimorfismo é o que envolve um único nucleotídeo, chamado de polimorfismo de nucleotídeo único, polimorfismo de transição ou SNPs (Single Nucleotide Polymorphisms), onde ocorre a substituição de um nucleotídeo por outro, ocorrendo a troca de um único par de bases, podendo ainda assim afetar a expressão de proteínas, a estrutura e a função de um gene (Takashiba e Naruishi, 2006). 
Os polimorfismos estão dispersos por todo o genoma e ocorrem em regiões codificadoras e não codificadoras. Nos polimorfismos de regiões codificadoras, denominados não-sinônimos, pode ocorrer uma substituição de um aminoácido na sequência protéica, podendo levar a modificações estruturais e funcionais na proteína e um a potencial efeito biológico. Alguns polimorfismos de regiões não codificadoras, classificados como sinônimos podem modificar a estrutura e estabilidade do RNA mensageiro e afetar a quantidade de proteína produzida. Outro tipo de polimorfismo também importante é aquele localizado em regiões promotoras, pois é capaz de alterar a expressão do gene (Chasman e Adams, 2001).

Sabe-se que quando o polimorfismo ocorre na região codificadora do gene, pode resultar na substituição de um aminoácido, alterando a síntese de uma proteína e podendo alterar a função celular (lota et al., 2015). Se a função das proteínas for afetada em um processo biológico, o polimorfismo de alguns genes pode aumentar ou diminuir o risco do paciente à expressão fenotípica da doença/alteração (Kinane e Hart, 2003).

Desta forma, é possível hipotetizar que polimorfismos genéticos localizados nas regiões reguladoras e codificadoras dos genes que codificam as proteínas envolvidas na osteoclastogênese (RANK/RANKL/OPG), poderiam estar associados às dimensões craniofaciais. 

2. Proposição 



\section{PROPOSIÇÃo}

\section{Objetivo Geral}

O objetivo do presente estudo foi avaliar, em humanos, a associação entre os polimorfismos rs3826620, rs9594738 e rs1235584, localizados nas regiões reguladoras e codificadoras dos genes que expressam RANK, RANKL e OPG, respectivamente, com as dimensões craniofaciais.

\section{Objetivos Específicos}

$\checkmark$ Avaliar a associação entre a medida angular SNA com os polimorfismos genéticos em RANK, RANKL e OPG.

$\checkmark$ Avaliar a associação entre a medida angular SNB com os polimorfismos genéticos em RANK, RANKL e OPG.

$\checkmark$ Avaliar se polimorfismos em RANK, RANKL e OPG estão associados com algum padrão esquelético específico (Classe I, Classe II ou Classe III), determinado por meio do ângulo ANB.

$\checkmark$ Avaliar a associação entre a medida linear Co-Gn, que representa o comprimento mandibular, com os polimorfismos genéticos em RANK, RANKL e OPG.

$\checkmark$ Avaliar a associação entre a medida linear Go-Pg, que representa o comprimento da base mandibular, com os polimorfismos genéticos em RANK, RANKL e OPG.

$\checkmark$ Avaliar a associação entre a medida linear Co-Go, que representa a altura do ramo mandibular, com os polimorfismos genéticos em RANK, RANKL e OPG.

$\checkmark$ Avaliar a associação entre a medida linear PTM-A, que representa o comprimento maxilar, com os polimorfismos genéticos em RANK, RANKL e OPG. 

3. Material e Métodos 



\section{Material e MÉtodos}

\section{Caracterização da amostra}

O presente estudo transversal foi previamente submetido à apreciação pelo Comitê de Ética em Pesquisa envolvendo Seres Humanos da Faculdade de Odontologia de Ribeirão Preto-Universidade de São Paulo (FORP/USP) (CAAE: 50765715.3.0000.5419 - Anexo A), tendo sido aprovado.

A amostra foi composta por 100 pacientes de ambos os gêneros, com faixa etária de13 a 51 anos, em tratamento ortodôntico no Curso de Especialização em Ortodontia e na Disciplina de Ortodontia Preventiva do Curso de Graduação em Odontologia da FORP/USP. Após assinatura do Termo de Consentimento Livre e Esclarecido (TCLE), pelos pacientes ou por seus responsáveis, foram obtidas informações como etnia, gênero e idade, a partir do prontuário de cada paciente.

\section{Critérios de inclusão e exclusão}

Pacientes com um conjunto completo de registros pré-tratamento ortodôntico, incluindo telerradiografia em norma lateral, fotografias intra e extrabucais e modelos de gesso foram incluídos no estudo. Não foram incluídos pacientes portadores de síndromes genéticas e/ou com doenças sistêmicas, e pacientes que não tiveram o TCLE assinado.

\section{Determinação do fenótipo}

As telerradiografias em norma lateral obtidas de cada paciente foram escaneadas, para realização dos traçados cefalométricos, por meio do scanner HP Scanjet G4050, para permitir a aquisição pelo sistema Dolphin ${ }^{\circledR}$ Imaging 11.0 (Dolphin Imagingand Management Solutions, Chatsworth, Calif., EUA). Durante a etapa de escaneamento das imagens, utilizou-se um indicador (régua milimetrada Dolphin ${ }^{\circledR}$ Radiographic Film Calibration Ruler), para determinar a quantidade de ampliação e estabelecer uma proporção da imagem escaneada. As imagens foram convertidas no formato JPEG e salvas com qualidade máxima, por meio do Dolphin ${ }^{\circledR}$ Imaging11.0. O tamanho do arquivo da imagem final foi de, aproximadamente, $200 \mathrm{~KB}$ e resolução de 200dpi, para obtenção das medidas angulares e lineares. 
Todos os traçados e medidas foram obtidos por um único examinador previamente calibrado (Kappa>0,9), especialista em Ortodontia. Foram utilizados os seguintes pontos:

- Ponto S (sela).

- Ponto N (násio).

- Ponto A (subespinhal).

- Ponto B (supramental).

- Ponto Go (gônio).

- Ponto Gn (gnátio).

- Ponto Co (condílio).

- Ponto Pg (pogônio).

- $\quad$ Ponto PTM (ponto mais superior e posterior da fossa pterigomaxilar).

As seguintes medidas lineares e angulares foram determinadas:

- Ângulo SNA: determinado pela intersecção das linhas SN e NA, expressando o grau de protrusão, retrusão ou bom posicionamento da maxila em relação à base do crânio (Riedel, 1952).

- Ângulo SNB: determinado pela intersecção das linhas SN e NB, expressando a posição ântero-posterior da mandíbula, em relação à base do crânio (Riedel, 1952).

- Ângulo ANB: para determinação da relação esquelética ântero-posterior da maxila e da mandíbula, com relação à base do crânio, classificado em classe I $\left(A N B=0\right.$ a $\left.4,5^{\circ}\right)$, classe II $\left(A N B>4,5^{\circ}\right)$ ou classe III $\left(A N B<0^{\circ}\right)$ (Tweed, 1966).

- Comprimento da maxila (PTM-A): determinado pela medida linear do ponto PTM até ponto A, em milímetros $(\mathrm{mm})$.

- Comprimento da mandíbula (Co-Gn): determinado pela medida linear do ponto Co até $\mathrm{Gn}$, em $\mathrm{mm}$.

- Comprimento da base da mandíbula (Go-Pg): determinado pela medida linear do pontoGo até $\mathrm{Pg}$, em $\mathrm{mm}$.

- Comprimento do ramo mandibular (Co-Go): determinado pela medida linear do ponto Co até Go, em $\mathrm{mm}$. 


\section{Coleta de material biológico para extração e quantificação do DNA}

Amostras de saliva não-estimulada foram coletadas de cada paciente, como fonte de DNA genômico, seguindo protocolo previamente estabelecido (Küchler et al., 2012). Para a coleta, os indivíduos realizaram bochecho com $5 \mathrm{~mL}$ de solução salina a 5\% durante 1 minuto, sendo o volume do bochecho acondicionado em tubos para centrífuga de 15mL (Corning Inc., Corning, NY, EUA).

Cada tubo contendo a saliva coletada foi centrifugado a 550rpm, durante 15 minutos, para sedimentação do pellet de células. O sobrenadante foi descartado e o pellet ressuspendido em $1 \mathrm{~mL}$ de tampão de extração (Tris- $\mathrm{HCl} 10 \mathrm{mM}, \mathrm{pH}$ 7,8; EDTA 5mM; SDS 0,5\%). A amostra foi, então, transferida para um microtubo plástico de 1,5mL (Axygen, Union city, CA, 94537, USA), o qual foi congelado a $-20^{\circ} \mathrm{C}$, até o momento da extração do DNA.

Posteriormente, as amostras foram descongeladas e incubadas com $100 \mathrm{ng} / \mathrm{mL}$ de Proteinase K $(4 \mu \mathrm{L}$ de Proteinase K - Promega Coporation, 2800 Woods Hollow Road, Madison, WI 53711-5399, USA), na concentração de 25mg/mL, em banho-maria a $56^{\circ} \mathrm{C}$ overnight e, então, submetidas a processos de precipitação, utilizando-se $400 \mu \mathrm{L}$ de solução de acetato de amônio a 10M. A seguir, todos os tubos foram agitados manualmente por 5 minutos e centrifugados por 15 minutos (12000rpm), sendo o sobrenadante dividido em dois microtubos plásticos de 1,5mL, contendo $700 \mu \mathrm{L}$ cada. O mesmo volume $(700 \mu \mathrm{L})$ de álcool isopropílico resfriado foi adicionado a cada microtubo, seguido de agitação vigorosa.

Após nova centrifugação por 20 minutos (1200 rpm) a $4^{\circ} \mathrm{C}$, a formação da "nuvem de DNA" foi observada nas alíquotas de cada microtubo plástico. Em seguida, o sobrenadante foi descartado com cuidado para não deslocar o pellet de DNA, e $1 \mathrm{~mL}$ de etanol a $70 \%$ resfriado foi adicionado, seguido de centrifugação por 15 minutos (12000rpm), a $4^{\circ} \mathrm{C}$. Posteriormente, o sobrenadante foi descartado, e o tubo aberto e emborcado em papel, para secagem e evaporação do excesso de etanol por, pelo menos, 30 minutos. Cada pellet de DNA foi ressuspendido em 400 $\mu \mathrm{L}$ de Tampão de Extração (TE) (Tris-HCl10mM; pH 7.8; EDTA 1mM) e congelado a $-20^{\circ} \mathrm{C}$.

A concentração e a pureza do DNA foram determinadas por densidade óptica em espectrofotômetro (NanoDrop ${ }^{\circledR} 2000$ cspectrophotometer, Thermo Fisher Scientifc, Foster City, CA), utilizando-se $2 \mu \mathrm{L}$ do material extraído, em comprimentos de onda de 260 e 280 nanômetros $(\mathrm{nm})$. A razão entre os valores obtidos nos 
comprimentos de onda de 260 e $280 \mathrm{~nm}$ foi usada para estimar a pureza do DNA genômico. A seguir, as amostras foram diluídas em água Milli-Q, a 2ng/ $\mu \mathrm{L}$.

Seleção dos Polimorfismos Genéticos a serem avaliados e Genotipagem por PCR em tempo Real

Os polimorfismos genéticos foram selecionados de acordo com a frequência alélica na população caucasiana (http://genome.ucsc.edu) e possível impacto biológico. As características dos polimorfismos genéticos a serem estudados, nos genes que codificam RANK, RANKL e OPG, estão apresentadas na Tabela 1. 
Tabela 1 - Descrição das características das variações genéticas estudadas

\begin{tabular}{|c|c|c|c|c|c|c|c|}
\hline & Nome do Gene & $\begin{array}{l}\text { Símbolo do } \\
\text { Gene }\end{array}$ & Polimorfismo & $\begin{array}{c}\text { Região } \\
\text { cromossômica }\end{array}$ & Sequência & $\begin{array}{l}\text { Heterozigosidade } \\
\text { média } \pm \text { erro } \\
\text { padrão }\end{array}$ & MAF \\
\hline RANK & $\begin{array}{c}\text { Tumor Necrosis Factor } \\
\text { Receptor Superfamily, } \\
\text { Member 11a, NFKB Activator }\end{array}$ & TNFRSF11A & rs3826620 & $18 q 21.33$ & GTGATTCAC[G/T]CTGCAGGCC & $0,454+/-0,144$ & 0,349 \\
\hline RANKL & $\begin{array}{l}\text { Tumor Necrosis Factor } \\
\text { Superfamily, Member } 11\end{array}$ & TNFSF11 & rs9594738 & $13 q 14.11$ & ATATCTGCTA[C/T]GAAGCTTTG & $0,407+/-0,194$ & 0,284 \\
\hline OPG & $\begin{array}{c}\text { Tumor Necrosis Factor } \\
\text { Receptor Superfamily } \\
\text { Member } 11 b\end{array}$ & TNFRSF11B & rs2073618 & $8 q .24 .12$ & AATGAACAA[듬]TTGCTGTGC & $0,444+/-0,157$ & 0,333 \\
\hline
\end{tabular}

Obtido a partir da base de dados: http://www.ncbi.nlm.nih.gov; http://genome.ucsc.edu. MAF: Minor Allele Frequency (Freqüência do Alelo Menor); letras em negrito e sublinhado indicam alelo mutante. ${ }^{\#}$ :Variante missense (troca de uma lisina por asparagina). 
Os polimorfismos selecionados foram genotipados por PCR (reação da polimerase em cadeia) em tempo real, usando o método Taqman (Ranade et al., 2001; Küchler et al., 2017). As amplificações foram realizadas no termociclador Step One Plus Real Time PCR System (Applied Biosystems - Foster City - CalifórniaUSA), no laboratório de "Biologia Molecular e Cultura de Células" do Departamento de Clínica Infantil, da FORP/USP.

$\mathrm{Na}$ análise de Taqman, duas sondas (VIC e FAM) são utilizadas no ensaio de discriminação alélica, onde cada sonda anela com a variante polimórfica específica. Durante o PCR, primers se hibridizam com a sequência alvo do DNA. Essa reação resulta na liberação de fluorescência específica de cada sonda e essa fluorescência é capturada e mensurada pelo termociclador, como consequência da amplificação do DNA alvo.

Todas as reações de PCR foram realizadas com um volume final de 3,4 $\mu \mathrm{L}$ (4ng de DNA, 2,5 $\mu \mathrm{L}$ de Taqman Genotyping Master Mix PCR, Applied biosystems by Thermo Fisher Scientifc, Foster City, CA 94404; 0,075 de sonda e água qsp). A condição de ciclo do PCR utilizada foi a seguinte: $95^{\circ} \mathrm{C}$ por 10 minutos, seguido por 40 ciclos de amplificação de $92^{\circ} \mathrm{C}$ por 15 segundos e $60^{\circ} \mathrm{C}$ por 1 minuto.

\section{Análise estatística}

Os dados foram analisados utilizando o Epi Info 3.5.2(Centers for Disease Controland Prevention-CDC, Atlanta, Georgia, USA) e o GraphPad Prism 5.0a (GraphPad Software Inc., San Diego, CA, USA).

O teste de Shapiro-Wilk foi utilizado para verificar a normalidade dos dados. Para avaliar a distribuição dos genótipos de acordo com os padrões esqueléticos faciais (Classe I, Classe II e Classe III) foi utilizado o teste do qui-quadrado.

Para comparar as médias das dimensões maxilares e mandibulares de acordo com os genótipos utilizou-se o teste de Kruskal-Wallis, com o pós-teste de Dunn para comparações múltiplas, ou ANOVA com pós-teste de Tukey.

Foi utilizada a análise de regressão linear multivariada para ajustar a possível influência da idade e do gênero nas medidas. O equilíbrio de Hardy-Weinberg foi avaliado utilizando o teste do qui-quadrado para cada polimorfismo.

O nível de significância adotado para todas as análises foi $5 \%$. 


\section{Resultados}





\section{Resultados}

Os polimorfismos rs3836620, rs9594738, rs2073618 em RANK, RANKL e OPG estavam em equilíbrio de Hardy-Weinberg.

As características da população estudada encontram-se apresentadas na tabela 2. Verifica-se que, quanto à distribuição dos gêneros, 50 (50\%) pacientes incluídos no estudo eram do gênero masculino e 50 (50\%) do gênero feminino. A média de idade dos indivíduos incluídos foi de 17,27 anos (DP 7,90 anos).

A medida angular SNA apresentou uma média de $83,19^{\circ}$ (DP 4,86), o SNB apresentou uma média de $80,48^{\circ}$ (DP 4,97) e o ANB uma média de $2,71^{\circ}$ (DP2,72).

Em relação ao padrão esquelético, foi observado que 57 indivíduos (57\%) eram Classe I, 29 (29\%) Classe II e 14 (14\%) eram Classe III.

O tamanho mandibular (Co-Gn) apresentou a média de 116,26mm (DP 11,74), a base mandibular (Go-Pg) apresentou a média de 68,90mm (DP 7,83) e 0 comprimento do ramo mandibular (Co-Go), apresentou a média de $58,27 \mathrm{~mm}$ (DP 7,96). O comprimento maxilar (PTM-A) apresentou a média de 50,32mm (DP 4,76).

\begin{tabular}{|c|c|}
\hline Gênero - n (\%) & \\
\hline Masculino & $50(50 \%)$ \\
\hline Feminino & $50(50 \%)$ \\
\hline Média de idade & $17,27(\mathrm{DP} 7,90)$ \\
\hline \multicolumn{2}{|c|}{ Média das medidas angulares (em graus) } \\
\hline SNA & 83,19 (DP 4,86) \\
\hline SNB & 80,48 (DP 4,97) \\
\hline ANB & $2,71(\mathrm{DP} 2,72)$ \\
\hline \multicolumn{2}{|c|}{ Padrão Esquelético - n (\%) } \\
\hline Classe I & $57(57 \%)$ \\
\hline Classe II & $29(29 \%)$ \\
\hline Classe III & $14(14 \%)$ \\
\hline \multicolumn{2}{|c|}{ Média das medidas lineares mandibulares (em $\mathrm{mm}$ ) } \\
\hline Co-Gn & $116,26(\mathrm{DP} 11,74)$ \\
\hline Go-Pg & 68,90 (DP 7,83) \\
\hline Co-Go & 58,27 (DP 7,96) \\
\hline \multicolumn{2}{|c|}{ Média da medida linear maxilar (em mm) } \\
\hline PTM-A & $50,32(\mathrm{DP} 4,76)$ \\
\hline
\end{tabular}

A Figura 1 apresenta a distribuição da média do ângulo SNA, de acordo com os genótipos em RANK, RANKL e OPG. Em nenhum dos genes houve diferença estatística significante entre os genótipos, para a medida angular SNA $(p>0,05)$. 
Figura 1 - Distribuição das médias do ângulo SNA, de acordo com os genótipos em RANK, RANKL e OPG. Não houve diferença estatística significante entre os genótipos $(p>0,05)$

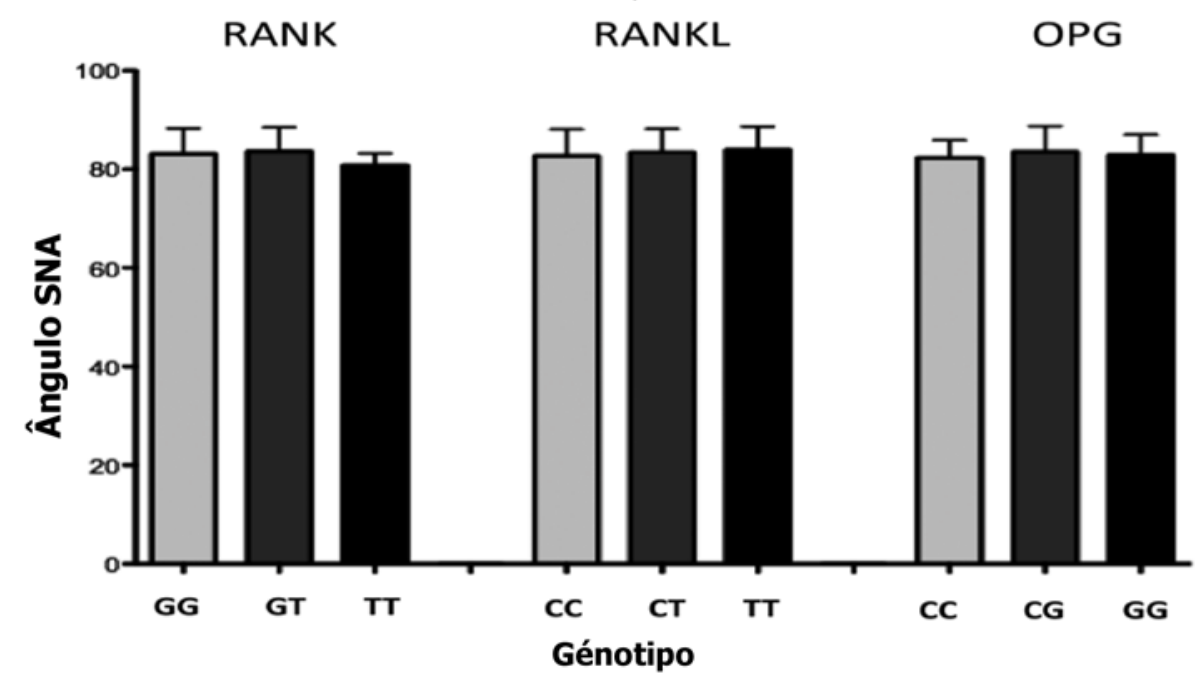

A Figura 2 apresenta a distribuição da média do ângulo SNB, de acordo com os genótipos em RANK, RANKL e OPG. Em nenhum dos genes houve diferença estatística significante entre os genótipos, para a medida angular SNB $(p>0,05)$.

Figura 2 - Distribuição das médias do ângulo SNB, de acordo com os genótipos em RANK, RANKL e OPG. Não houve diferença estatística entre os genótipos $(p>0,05)$

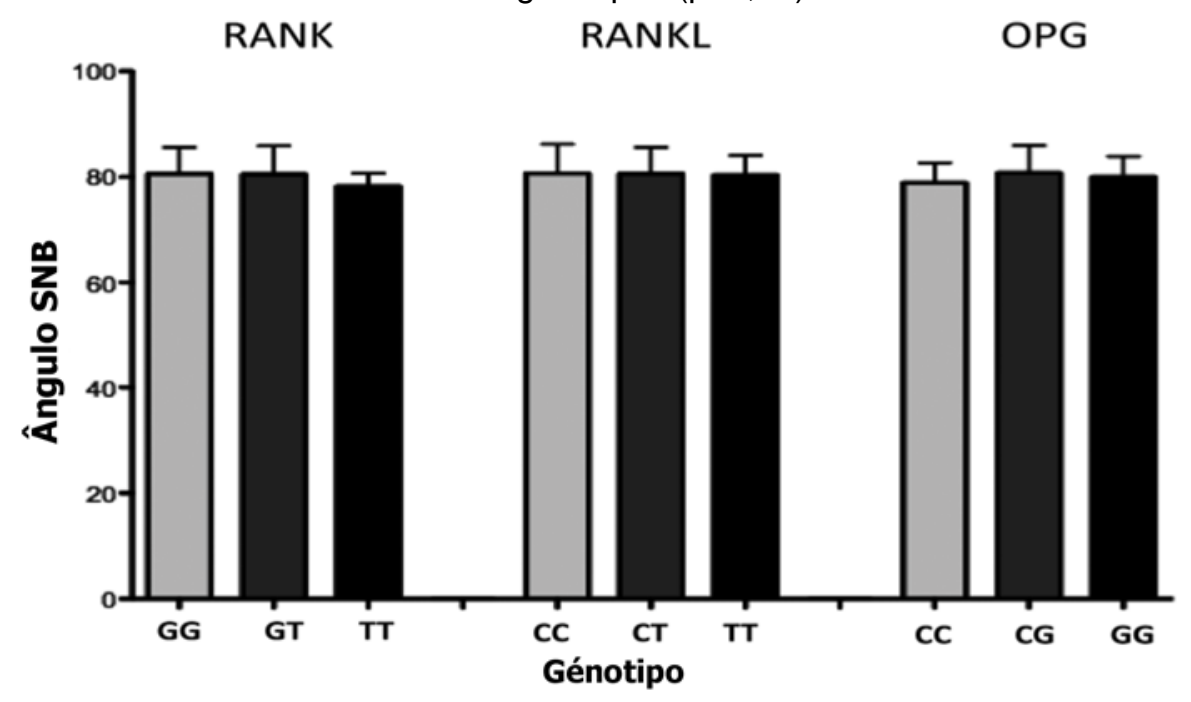

A distribuição genotípica de RANK, RANKL e OPG, de acordo com a distribuição fenotípica (padrão esquelético Classe I, Classe II ou Classe III) está apresentada na tabela 3. Não foi possível evidenciar diferença significante entre as distribuições genotípicas dos polimorfismos estudados (rs3826620, rs9594738 e rs2073618)e os diferentes padrões esqueléticos faciais ( $p>0,05)$. 
Tabela 3- Distribuição genotípica de RANK, RANKL e OPG, de acordo com o padrão esquelético facial(Classe I, Classe II ou Classe III)

\begin{tabular}{|c|c|c|c|c|c|}
\hline Gene & Genótipo & $\begin{array}{c}\text { Classe I } \\
\text { n (\%) }\end{array}$ & $\begin{array}{c}\text { Classe II } \\
\text { n (\%) }\end{array}$ & $\begin{array}{c}\text { Classe III } \\
\text { n (\%) }\end{array}$ & p-valor \\
\hline \multirow{3}{*}{ RANK } & GG & $26(49,1)$ & $16(55,2)$ & $8(57,1)$ & \multirow{3}{*}{0,815} \\
\hline & GT & $23(43,4)$ & $11(37,9)$ & $4(28,6)$ & \\
\hline & TT & $4(7,5)$ & $2(6,9)$ & $2(14,3)$ & \\
\hline \multirow{3}{*}{ RANKL } & $\mathrm{CC}$ & $15(28,8)$ & $7(25,9)$ & $7(50,0)$ & \multirow{3}{*}{0,361} \\
\hline & CT & $30(57,7)$ & $16(59,3)$ & $4(28,6)$ & \\
\hline & TT & $7(13,5)$ & $4(14,8)$ & $3(21,4)$ & \\
\hline \multirow{3}{*}{ OPG } & $\mathrm{CC}$ & $16(29,6)$ & $8(28,6)$ & $3(25,0)$ & \multirow{3}{*}{0,955} \\
\hline & CG & $26(48,1)$ & $13(46,4)$ & $5(41,7)$ & \\
\hline & GG & $12(22,2)$ & $7(25,0)$ & $7(33,3)$ & \\
\hline
\end{tabular}

A distribuição alélica de RANK, RANKL e OPG, de acordo com o padrão esquelético facial (Classe I, Classe II ou Classe III), encontra-se apresentada na tabela 4. Não foi possível evidenciar diferença significante entre as distribuições alélicas dos polimorfismos estudados (rs3826620, rs9594738 e rs2073618) e os diferentes padrões esqueléticos faciais $(p>0,05)$.

Tabela 4 - Distribuição alélica de RANK, RANKL e OPG, de acordo com o padrão esquelético facial(Classe I, Classe II ou Classe III)

\begin{tabular}{|c|c|c|c|c|c|}
\hline Gene & Genótipo & $\begin{array}{c}\text { Classe I } \\
\text { n (\%) }\end{array}$ & $\begin{array}{c}\text { Classe II } \\
\text { n (\%) }\end{array}$ & $\begin{array}{c}\text { Classe III } \\
\text { n (\%) }\end{array}$ & p-valor \\
\hline RANK & $\begin{array}{l}\mathrm{G} \\
T\end{array}$ & $\begin{array}{l}75(70,75) \\
31(29,25)\end{array}$ & $\begin{array}{l}43(74,13) \\
15(25,87)\end{array}$ & $\begin{array}{c}20(71,42) \\
8(28,58)\end{array}$ & 0,897 \\
\hline RANKL & $\begin{array}{l}\mathrm{G} \\
\mathrm{T}\end{array}$ & $\begin{array}{l}90(67,16) \\
44(32,84)\end{array}$ & $\begin{array}{l}30(55,55) \\
24(44,45) \\
\end{array}$ & $\begin{array}{l}18(64,28) \\
10(35,72)\end{array}$ & 0,324 \\
\hline OPG & $\begin{array}{l}G \\
T\end{array}$ & $\begin{array}{l}58(53,70) \\
50(46,30)\end{array}$ & $\begin{array}{l}29(51,79) \\
27(48,21)\end{array}$ & $\begin{array}{l}11(45,83) \\
13(54,17)\end{array}$ & 0,782 \\
\hline
\end{tabular}

As Tabelas 5, 6 e 7 apresentam a distribuição das médias das medidas lineares maxilares e mandibulares, de acordo com o genótipo dos genes que codificam RANK, RANKL e OPG.

Na tabela 5, onde não foi realizada distinção entre os gêneros, observou-se uma diferença estatisticamente significante entre a distribuição das medidas do comprimento da base mandibular (Go-Pg), de acordo com os genótipos de RANK. O genótipo GG apresentou maior medida de Go-Pg ( $p=0,039)$.

A análise da distribuição das médias das medidas maxilares e mandibulares também foi realizada de forma estratificada, de acordo com o gênero. A tabela 6 apresenta a distribuição das médias de acordo com os genótipos para o gênero feminino. Não foi observada diferença significante entre as médias, de acordo com os genótipos de RANK, RANKL e OPG $(p>0,05)$. A tabela 7 apresenta a distribuição 
das médias de acordo com os genótipos para o gênero masculino. Não foi observada diferença significante entre as médias, de acordo com os genótipos de RANK, RANKL e OPG ( $p>0,05)$.

A interação gene-gene também foi avaliada. A interação entre os polimorfismos em RANK, RANKL e OPG foi associada com uma maior medida de Go-Pg $(p=0,04)$. 
Tabela 5 - Associação entre os polimorfismos em RANK, RANKL e OPG e as medidas lineares

\begin{tabular}{|c|c|c|c|c|c|c|c|c|c|c|}
\hline & & & \multicolumn{2}{|c|}{ Co-Gn (mm) } & \multicolumn{2}{|l|}{ Go-Pg (mm) } & \multicolumn{2}{|c|}{ Co-Go (mm) } & \multicolumn{2}{|c|}{ PTM-A (mm) } \\
\hline Gene & Genótipo & $\mathbf{n}$ & Média (DP) & p-valor & Média (DP) & p-valor & Média (DP) & p-valor & Média (DP) & p-valor \\
\hline \multirow{3}{*}{ RANK } & GG & 50 & $118,44(13,54)$ & & $70,86(8,70)$ & & $59,41(8,52)$ & & $59,41(8,52)$ & \\
\hline & GT & 38 & $113,38(8,59)$ & 0,352 & $66,73(6,57)$ & $0,039 *$ & $57,22(6,97)$ & 0,364 & $49,79(5,08)$ & 0,508 \\
\hline & TT & 8 & $115,51(12,33)$ & & $66,77(6,81)$ & & $57,80(9,26)$ & & $50,37(2,71)$ & \\
\hline \multirow{3}{*}{ RANKL } & $\mathrm{CC}$ & 29 & $117,90(14,04)$ & & $69,27(8,97)$ & & $60,16(9,95)$ & & $50,49(4,34)$ & \\
\hline & CT & 50 & $115,04(9,97)$ & 0,764 & $68,70(6,61)$ & 0,867 & $57,83(7,65)$ & 0,799 & $49,78(4,80)$ & 0,567 \\
\hline & TT & 14 & $119,58(13,88)$ & & $71,32(9,18)$ & & $57,24(4,93)$ & & $52,16(6,24)$ & \\
\hline \multirow{3}{*}{ OPG } & $\mathrm{CC}$ & 27 & $113,61(10,38)$ & & $65,97(8,15)$ & & $57,94(6,85)$ & & $49,96(4,67)$ & \\
\hline & CG & 44 & $115,99(10,37)$ & 0,699 & $69,73(7,22)$ & 0,075 & $57,23(7,23)$ & 0,806 & $50,44(5,24)$ & 0,799 \\
\hline & GG & 23 & $115,15(9,06)$ & & $68,72(5,69)$ & & $58,13(7,22)$ & & $49,81(3,44)$ & \\
\hline
\end{tabular}

*: diferença estatisticamente significante. 
Tabela 6 - Associação entre os polimorfismos em RANK, RANKL e OPG e as medidas lineares no gênero feminino

\begin{tabular}{|c|c|c|c|c|c|c|c|c|c|c|}
\hline \multirow{2}{*}{ Gene } & \multirow[b]{2}{*}{ Genótipo } & \multirow[b]{2}{*}{$\mathbf{n}$} & \multicolumn{2}{|c|}{ Co-Gn (mm) } & \multicolumn{2}{|l|}{ Go-Pg (mm) } & \multicolumn{2}{|c|}{ Co-Go (mm) } & \multicolumn{2}{|c|}{ PTM-A (mm) } \\
\hline & & & Média (DP) & p-valor & Média (DP) & p-valor & Média (DP) & p-valor & Média (DP) & p-valor \\
\hline & GG & 26 & $112,91(9,36)$ & & $68,42(7,19)$ & & $55,54(5,40)$ & & $49,61(5,14)$ & \\
\hline \multirow[t]{2}{*}{ RANK } & GT & 18 & $111,38(7,55)$ & 0,76 & $66,08(6,55)$ & 0,34 & $54,88(4,71)$ & 0,29 & $49,46(4,35)$ & 0,99 \\
\hline & TT & 4 & $114,25(7,24)$ & & $64,15(2,98)$ & & $59,62(8,30)$ & & $49,77(3,45)$ & \\
\hline \multirow{3}{*}{ RANKL } & $\mathrm{CC}$ & 17 & $112,14(6,46)$ & & $66,64(6,83)$ & & $56,04(5,23)$ & & $49,44(3,94)$ & \\
\hline & CT & 22 & $111,87(6,96)$ & 0,47 & $67,48(4,84)$ & 0,57 & $55,05(6,12)$ & 0,84 & $48,70(4,11)$ & 0,44 \\
\hline & TT & 9 & $115,71(13,03)$ & & $69,38(8,25)$ & & $55,92(4,98)$ & & $51,14(7,31)$ & \\
\hline \multirow{3}{*}{ OPG } & $\mathrm{CC}$ & 17 & $112,02(8,25)$ & & $64,41(7,28)$ & & $57,05(5,78)$ & & $49,12(4,12)$ & \\
\hline & CG & 21 & $113,20(9,96)$ & 0,85 & $69,26(6,78)$ & 0,08 & $54,36(5,66)$ & 0,33 & $50,33(5,66)$ & 0,53 \\
\hline & GG & 10 & $111,57(5,40)$ & & $67,57(4,19)$ & & $55,13(4,87)$ & & $48,41(3,51)$ & \\
\hline
\end{tabular}


Tabela 7 - Associação entre os polimorfismos em RANK, RANKL e OPG e as medidas lineares no gênero masculino

\begin{tabular}{|c|c|c|c|c|c|c|c|c|c|c|}
\hline \multirow[b]{2}{*}{ Gene } & \multirow[b]{2}{*}{ Genótipo } & \multirow[b]{2}{*}{$\mathbf{n}$} & \multicolumn{2}{|c|}{ Co-Gn (mm) } & \multicolumn{2}{|l|}{ Go-Pg (mm) } & \multicolumn{2}{|c|}{ Co-Go (mm) } & \multicolumn{2}{|c|}{ PTM-A (mm) } \\
\hline & & & Média (DP) & p-valor & Média (DP) & p-valor & Média (DP) & p-valor & Média (DP) & p-valor \\
\hline & GG & 24 & $124,43(14,94)$ & & $73,50(9,54)$ & & $63,60(9,36)$ & & $52,46(3,97)$ & \\
\hline \multirow[t]{2}{*}{ RANK } & GT & 20 & $115,19(9,24)$ & 0,06 & $67,32(6,70)$ & 0,06 & $59,32(8,06)$ & 0,15 & $50,09(5,75)$ & 0,26 \\
\hline & TT & 4 & $116,77(17,27)$ & & $69,40(9,00)$ & & $55,97(11,05)$ & & $50,97(2,07)$ & \\
\hline \multirow{3}{*}{ RANKL } & $\mathrm{CC}$ & 12 & $126,06(17,82)$ & & $73,00(10,55)$ & & $66,01(10,55)$ & & $51,98(4,60)$ & \\
\hline & СТ & 28 & $117,52(11,32)$ & 0,12 & $69,65(7,68)$ & 0,34 & $60,01(8,12)$ & 0,15 & $50,63(5,19)$ & 0,33 \\
\hline & TT & 5 & $126,56(13,85)$ & & $74,82(10,68)$ & & $59,62(4,27)$ & & $54,00(3,63)$ & \\
\hline \multirow{3}{*}{ OPG } & $\mathrm{CC}$ & 10 & $116,31(13,31)$ & & $68,64(9,22)$ & & $59,46(8,48)$ & & $51,39(5,40)$ & \\
\hline & CG & 23 & $118,54(10,29)$ & 0,86 & $70,15(7,73)$ & 0,87 & $59,86(7,62)$ & 0,95 & $50,54(4,95)$ & 0,88 \\
\hline & GG & 13 & $117,90(10,47)$ & & $69,60(6,65)$ & & $60,43(8,03)$ & & $50,89(3,09)$ & \\
\hline
\end{tabular}


A análise de regressão linear multivariada foi realizada utilizando o gênero e a idade como co-variáveis (Tabela 8). Verificou-se que o gênero influenciou nos resultados $(p<0,05)$, porém a idade não influenciou $(p>0,05)$.

Além disso, o polimorfismo no gene RANK esteve associado com as dimensões mandibulares, onde o gênero apresentou forte associação com essas dimensões. Nesta análise, foi possível evidenciar que o genótipo GT em RANK foi associado com a medida Co-Gn ( $p=0,043)$ e com a medida Go-Pg $(p=0,017)$.

Tabela 8 - Análise de regressão linear multivariada para análise da influência do gênero e idade

\begin{tabular}{|c|c|c|c|c|c|c|}
\hline \multirow[b]{2}{*}{ Gene } & \multicolumn{2}{|c|}{ Genótipo } & \multicolumn{2}{|c|}{ Gênero } & \multicolumn{2}{|c|}{ Idade } \\
\hline & Coeficiente & p-valor & Coeficiente & p-valor & Coeficiente & p-valor \\
\hline \multicolumn{7}{|c|}{ PTM-A } \\
\hline RANK (GT/GG) & $-1,302$ & 0,217 & $-1,765$ & 0,074 & 0,009 & 0,881 \\
\hline RANK (TT/GG) & $-0,603$ & 0,739 & & & & \\
\hline RANKL (CT/CC) & $-0,938$ & 0,414 & $-2,133$ & 0,039 & 0,027 & 0,664 \\
\hline RANKL (CT/CC) & 1,893 & 0,233 & & & & \\
\hline OPG (CG/CC) & $-0,089$ & 0,938 & $-1,279$ & 0,198 & 0,009 & 0,884 \\
\hline OPG (GG/CC) & $-0,600$ & 0,657 & & & & \\
\hline \multicolumn{7}{|c|}{ Co-Gn } \\
\hline RANK (GT/GG) & $-4,967$ & $0,043^{*}$ & $-7,587$ & $0,001^{*}$ & 0,247 & 0,087 \\
\hline RANK (TT/GG) & $-3,115$ & 0,459 & & & & \\
\hline RANKL (CT/CC) & $-3,782$ & 0,152 & $-8,606$ & $>0,001$ & 0,284 & 0,049 \\
\hline RANKL (CT/CC) & 2,419 & 0,504 & & & & \\
\hline OPG (CG/CC) & 0,490 & 0,836 & $-5,355$ & 0,010 & 0,197 & 0,129 \\
\hline OPG (GG/CC) & $-0,751$ & 0,788 & & & & \\
\hline \multicolumn{7}{|c|}{ Co-Go } \\
\hline RANK (GT/GG) & $-2,487$ & 0,134 & $-5,541$ & $>0,001$ & 0,134 & 0,167 \\
\hline RANK (TT/GG) & $-1,841$ & 0,518 & & & & \\
\hline RANKL (CT/CC) & $-3,299$ & 0,066 & $-6,120$ & $>0,001$ & 0,167 & 0,087 \\
\hline RANKL (CT/CC) & $-2,577$ & 0,294 & & & & \\
\hline OPG (CG/CC) & $-1,936$ & 0,241 & $-4,505$ & 0,001 & 0,122 & 0,174 \\
\hline OPG (GG/CC) & $-1,254$ & 0,516 & & & & \\
\hline \multicolumn{7}{|c|}{ Go-Pg } \\
\hline RANK (GT/GG) & $-4,049$ & $0,017^{*}$ & $-3,518$ & $0,026 *$ & 0,153 & 0,122 \\
\hline RANK (TT/GG) & $-4,183$ & 0,149 & & & & \\
\hline RANKL (CT/CC) & $-1,075$ & 0,549 & $-3,757$ & 0,0211 & 0,167 & 0,090 \\
\hline RANKL (CT/CC) & 2,309 & 0,351 & & & & \\
\hline OPG (CG/CC) & 2,967 & $0,093^{*}$ & $-2,211$ & 0,144 & 0,112 & 0,240 \\
\hline OPG (GG/CC) & 1,576 & 0,444 & & & & \\
\hline
\end{tabular}

Negrito e *: diferença estatística significante para os genótipos $(p<0,05)$. 
5. $D_{\text {iscussão }}$ 



\section{DISCUSSÃO}

\section{Da Metodologia}

O presente trabalho é um estudo de associação entre genótipos e alelos em polimorfismos do sistema RANK/RANKL/OPG. Estudos de associação são ferramentas para a identificação de polimorfismos genéticos que predispõem a alterações complexas, como as dimensões craniofaciais que interferem diretamente nos aspectos morfológicos das bases ósseas. Esses estudos podem ser realizados avaliando famílias de indivíduos ou indivíduos não relacionados entre si, como no presente trabalho, sendo denominados de caso-controle. Os estudos com indivíduos não relacionados biologicamente são mais frequentemente utilizados por permitirem um recrutamento de um maior número de indivíduos. Estudos com famílias são mais complexos, pois o acesso a todos os membros se torna mais difícil (Risch, 2000).

A amostra do presente estudo foi realizada por acessibilidade (amostra por conveniência). Este tipo de amostragem não probabilística é destituída de qualquer rigor estatístico, tendo em vista que o pesquisador seleciona os elementos a que tem acesso, admitindo que estes possam representar um universo. No entanto, a amostragem por conveniência é adequada e frequentemente utilizada em pesquisas exploratórias (Suenet al., 2014), como no caso do presente estudo, que foi o primeiro na literatura específica a avaliar a associação entre polimorfismos genéticos nos genes RANK, RANKL e OPG com as dimensões craniofaciais, em humanos.

O presente estudo foi realizado com uma amostra de caucasianos, não sendo incluídas outras etnias para reduzir a interferência nos resultados obtidos, pois sabe-se que as dimensões maxilares e mandibulares variam de acordo com a etnia. Outro fator a ser considerado é a idade dos pacientes selecionados. Apesar da possível suposição de que a idade influencia nas dimensões craniofaciais, no presente estudo a regressão linear multivariada evidenciou que a idade não influenciou nos resultados obtidos.

Paralelamente, a genotipagem no presente estudo foi realizada por meio do método Taqman, proposto por Ranade et al., em 2001. Esse método consiste na utilização de sondas fluorescentes alelo-específicas, que combinam as etapas de amplificação e detecção dos alelos em uma única 
etapa, eliminando a necessidade de procedimentos adicionais para a determinação do genótipo. A fluorescência é medida durante a reação de PCR e os genótipos inferidos a partir desses valores. Desta forma, o método Taqman elimina viés por erro de interpretação, pois os genótipos são gerados automaticamente, sem interferência da análise humana. Esta é uma técnica dispendiosa, devido à necessidade de se usar um equipamento especial com filtros para detecção de fluorescências em diferentes comprimentos de onda, e de alto custo para aquisição das sondas fluorescentes (Ranade et al., 2001). No presente estudo, o método Taqman foi utilizado pela simplicidade da técnica, pela alta especificidade e pela confiabilidade dos resultados, que fazem com que seja uma importante ferramenta para o estudo de associação de diversos genes com alterações e doenças. Atualmente, essa técnica vem sendo utilizada, inclusive por nosso grupo de Pesquisa, para o estudo de diversos fenótipos em Odontologia, como a cárie dentária (Lips et al., 2017; Antunes et al., 2017) e a fluorose dentária (Küchler et al., 2017).

Por outro lado, a cefalometria é o método que estuda as dimensões do crânio e da face, sendo amplamente utilizada nos estudos em Ortodontia que visam analisar as variações individuais nas dimensões maxilares e mandibulares (Li et al., 2010; Costa et al., 2017; Cruz et al., 2017).

Cabe ressaltar que as medidas cefalométricas utilizadas para a avaliação das dimensões maxilares e mandibulares, no presente estudo, foram selecionadas com base em uma revisão sistemática da literatura, previamente realizada (Nascimento et al., 2016), que demonstrou que estas são as medidas mais utilizadas para o estudo de associação de polimorfismos genéticos com dimensões maxilares e mandibulares. As medidas PTM-A, Co-Gn, Go-Pg e CoGo são medidascefalométricasem2D,que representam o comprimento maxilar, o comprimento mandibular, o comprimento da base da mandíbula e a altura do ramo mandibular, respectivamente.

\section{Dos Resultados}

Os dados do presente estudo sugerem que o polimorfismo rs3826620 em RANK, localizado no cromossomo 18, está envolvido com o aumento no comprimento mandibular e na base mandibular. Estudos anteriores coma análise do genoma em populações humanas forneceram evidências da 
associação do prognatismo mandibular com alguns cromossomos como 1, 3, 5, 11, 12 e 19 (Yamaguchi et al., 2005; Frazier-Bowers et al., 2009; Li et al., 2011). Além disso, alguns estudos avaliaram determinados genes candidatos como o MYO1H, que codifica a proteína muscular miosina1(TassopoulouFishell et al., 2012; DaFontoura et al, 2015),o COLs, que codifica o colágeno (Xue et al., 2014 ; DaFontoura et al., 2015), ADAMTS1, que codifica a desintegrina e a metaloproteinasecomtrombospondina(Guan et al., 2015), e o GHR, gene que codifica o receptor do hormônio de crescimento (Yamaguchi et al., 2001; Kang et al., 2009; Tomoyasu et al., 2009), verificando sua possível influência no tamanho mandibular.

No presente estudo, decidiu-se avaliar os polimorfismos no sistema de sinalização RANK/RANLKL/OPG, devido à sua importante função no metabolismo ósseo. Em meados de 1990, o sistema de sinalização RANK/RANKL/OPG foi identificado, proporcionando um grande avanço no conhecimento na área de biologia óssea e esclarecendo o papel desempenhado pelos osteoclastos nos processos de remodelação óssea (Boyce e Xing, 2008).

As análises univariadas e multivariadas realizadas no presente estudo demonstraram que polimorfismos no sistema de sinalização RANK/RANKL/ OPG podem estar envolvidos com as medidas mandibulares. O alfa adotado neste estudo foi de 5\%. Além disso, não foi realizada uma correção pós-teste, como a correção de Bonferroni, pois isso poderia aumentar a chance de erro tipo I. No entanto, é importante esclarecer que esta é uma estratégia importante para procurar polimorfismos associados aos "genes de pequeno efeito". Genes de pequeno efeito são genes cujos polimorfismos afetam coletivamente alguma característica de interesse. Muitos fenótipos humanos dependem da ação de alguns genes, mas das ações de muitos polimorfismos, cada um com um pequeno efeito sobre a característica geral. É razoável supor que dezenas de polimorfismos genéticos desempenham um papel nas dimensões da maxila e da mandíbula, uma vez que muitos caminhos envolvidos na regulação hormonal, a função muscular e o desenvolvimento ósseo podem estar envolvidos nas dimensões craniofaciais. Além disso, nas últimas décadas, polimorfismos na codificação de genes para o receptor hormonal (Yamaguchi et al., 2001;Tomoyasu et al., 2009; Kang et al., 
2009;Bayram et al., 2014;Zebrick et al., 2014) e genes que desempenham um papel na função muscular (Tassopoulou-Fishell et al., 2012;Arun et al., 2016) têm sido associados às dimensões mandibulares. Devido à importante função do sistema de sinalização RANK/RANKL/OPG na biologia óssea é possível hipotetizar que polimorfismos nestes genes poderiam contribuir nas dimensões craniofaciais.

Pallares et al. (2015) utilizaram morfometria craniofacial para mapear os genes envolvidos na determinação da forma, em uma população de camundongos, o que apontou Mn1 e Cldn18 como genes candidatos para a variação das dimensões craniofaciais. De fato, Mn1 e Cldn18 estão envolvidos na via de sinalização RANK/RANKL/OPG. Mn1 regula a expressão de RANKL pela estimulação do promotor de RANKL (Zhang et al., 2009) e Cldn18 regula a diferenciação de osteoclastos induzida por RANKL (Wongdee et al., 2008). Em nosso estudo, o polimorfismo rs3826620 em RANK foi associado com medidas mandibulares maiores, nas análises univariada e multivariada.

Por outro lado, sabe-se que a OPG age como um receptor antagônico natural que bloqueia os efeitos de RANKL. RANKL aumenta a produção, a atividade e a sobrevivência dos osteoclastos (Boyce e Xing, 2008). Portanto, os polimorfismos que diminuem a atividade da OPG teriam um impacto no osso, devido ao aumento da reabsorção (Roshandel et al., 2011). Em nosso estudo, o polimorfismo rs2073618 em OPG teve uma associação limítrofe com à medida mandibular, porém sem significância estatística.

Um estudo anterior realizado por Zhao et al. (2005) avaliou a densidade mineral óssea em mulheres e concluiu que o genótipo Asn-Asn do polimorfismo rs2073618 em OPG estava associado com níveis séricos menores de OPG, em comparação com o genótipo Lys-Lys. Outro estudo realizado por Roshandel et al., em 2011, também demonstrou que este genótipo foi associado com um maior turnover ósseo. Em nosso estudo, indivíduos que carrearam pelo menos um alelo G em OPG tiveram maiores medidas da mandíbula, entretanto sem associação estatística.

Outro fato importante a destacar é o fato de que as medidas da maxila não foram associadas aos polimorfismos estudados. Isso poderia significar que esses polimorfismos não estão envolvidos nas dimensões da maxila, ou pode estar relacionado com limitações do presente estudo, que se limitou a uma 
única medida linear (PTM-A), realizada em Raios-X bidimensionais. Futuros estudos com imagens 3D e maior número de medidas envolvidas podem permitir uma análise genética mais ampla das dimensões da maxila e, também, da mandíbula.

Adicionalmente, no presente estudo, os polimorfismos avaliados em RANK, RANKL e OPG não influenciaram no padrão facial (Classe I, II ou III), indicando que outros genes ou outros polimorfismos, que não os avaliados no presente estudo, influenciam nas dimensões maxilares, ou que o número de indivíduos que participaram do presente estudo foi pequeno, não possibilitando a observação de diferenças.

Finalizando, os resultados obtidos no presente estudo, onde observouse que o polimorfismo em RANK influenciou no aumento do comprimento mandibular (Co-Gn) e da base mandibular (Go-Pg), são relevantes e apresentam aplicabilidade clínica pois sabe-se que, na área da Ortodontia, um dos aspectos mais desafiadores no tratamento de pacientes é predizer o crescimento mandibular. A identificação de novos genes envolvidos nas dimensões mandibulares pode auxiliar na previsão do crescimento desse osso, conduzindo a melhores resultados de tratamentos, na prática clínica ortodôntica. 

6. Conclusão 



\section{CONCLUSÃO}

Com base na metodologia empregada e nos resultados obtidos, pôde-se concluir que houve associação entre o polimorfismo genético (rs3826620) em RANK com maiores dimensões mandibulares, onde o comprimento da mandíbula (Co-Gn) e o comprimento da base da mandíbula (Go-Pg) estavam aumentados. 

Referências 



\section{REFERÊNCIAS}

Adhikari K, Fuentes-Guajardo M, Quinto-Sánchez M, Mendoza-Revilla J, Camilo Chacón-Duque J, Acuña-Alonzo V, et al. A genome-wide association scan implicates DCHS2, RUNX2, GLI3, PAX1 and EDAR in human facial variation. Nat Commun. 2016;7:11616.

Arun RM, Lakkakula BV, Chitharanjan AB. Role of myosin $1 \mathrm{H}$ gene polymorphisms in mandibular retrognathism. Am J Orthod Dentofacial Orthop. 2016;149(5):699-704.

Antunes LA, Machado CM, Couto AC, Lopes LB, Sena FC, Abreu FV, et al. A Polymorphism in the MTRR Gene Is Associated with Early Childhood Caries and Underweight. Caries Res. 2017;51(2):102-8.

Bayram S, Basciftci FA, Kurar E. Relationship between P561T and C422F polymorphisms in growth hormone receptor gene and mandibular prognathism. Angle Orthod. 2014;84(5):803-9.

Boyce BF, Rosenberg E, de Papp AE, Duong LT. The osteoclast, bone remodelling and treatment of metabolic bone disease. Eur J Clin Invest. 2012;42(12):1332-41.

Boyce BF, Xing L. Functions of RANKL/RANK/OPG in bone modeling and remodeling. Arch Biochem Biophys. 2008;473(2):139-46.

Cakan DG, Ulkur F, Taner T. The genetic basis of facial skeletal characteristics and its relation with orthodontics. Eur J Dent. 2012 Jul; 6(3): 340-345.

Chasman D, Adams RM.Predicting the functional consequences of non-synonymous single nucleotide polymorphisms: structure-based assessment of amino acid variation.J Mol Biol 2001;307(2):683-706.

Consolaro A. Inflamação e reparo: um sílabo para a compreensão clínica e implicações terapêuticas. Maringá: Dental Press; 2009.

Costa AMG, Trevisan M, Matsumoto MAN, Silva RABS, Silva LABS, Horta KC et al., Association between Tooth Agenesis and Skeletal Malocclusions.J Oral Maxillofac Res 2017; 8(2):e3.

Cruz RM, Hartsfield JK, Falcão-Alencar G, Koller DL, Pereira RW, Mah J, et al. Exclusion of Class III malocclusion candidate loci in Brazilian families. J Dent Res. 2011;90(10):1202-5.

Cruz CV, Mattos CT, Maia JC, Granjeiro JM, Reis MF, Mucha JN, et al. Genetic polymorphisms underlying the skeletal Class III phenotype. Am J Orthod Dentofacial Orthop. 2017;151(4):700-7.

da Fontoura CS, Miller SF, Wehby GL, Amendt BA, Holton NE, Southard TE, et al. Candidate Gene Analyses of Skeletal Variation in Malocclusion. J Dent Res. 2015;94(7):913-20. 
Frazier-Bowers S, Rincon-Rodriguez R, Zhou J, Alexander K, Lange E. Evidence of linkage in a Hispanic cohort with a Class III dentofacial phenotype. J Dent Res. 2009;88(1):56-60.

Ferreira NO, Andrucioli MC, Nelson-Filho P, Zanella EP, Consolaro A, Romano FL, et al. Bacterial biofilm on successful and failed orthodontic mini-implants - a scanning electron microscopy study. Microsc Res Tech. 2015;78(12):1112-6.

Guan X, Song Y, Ott J, Zhang Y, Li C, Xin T, et al. The ADAMTS1 gene is associated with familial mandibular prognathism. J Dent Res. 2015;94(9):1196-201.

Hofbauer LC, Heufelder AE. The role of osteoprotegerin and receptor activator of nuclear factor kappaB ligand in the pathogenesis and treatment of rheumatoid arthritis. Arthritis Rheum. 2001;44(2):253-9.

Huh A, Horton MJ, Cuenco KT, Raoul G, Rowlerson AM, Ferri J, et al. Epigenetic influence of KAT6B and HDAC4 in the development of skeletal malocclusion. Am J Orthod Dentofacial Orthop. 2013;144(4):568-76.

Ikuta T, Inagaki Y, Tanaka K, Saito T, Nakajima $Y$, Bando $M$, et al. Gene polymorphism of $\beta$-defensin- 1 is associated with susceptibility to periodontitis in Japanese. Odontology. 2015;103(1):66-74.

Ikuno K, Kajii TS, Oka A, Inoko H, Ishikawa $\mathrm{H}$, lida J. Microsatellite genome-wide association study for mandibular prognathism. Am J Orthod Dentofacial Orthop. 2014;145(6):757-62.

Jang JY, Park EK, Ryoo HM, Shin HI, Kim TH, Jang JS, et al. Polymorphisms in the Matrilin-1 gene and risk of mandibular prognathism in Koreans. J Dent Res. 2010;89(11):1203-7.

Kang EH, Yamaguchi T, Tajima A, Nakajima T, Tomoyasu Y, Watanabe M, et al. Association of the growth hormone receptor gene polymorphisms with mandibular height in a Korean population. Arch Oral Biol. 2009;54(6):556-62.

Kearns AE, Khosla S, Kostenuik PJ. Receptor activator of nuclear factor kappaB ligand and osteoprotegerin regulation of bone remodeling in health and disease. Endocr Rev. 2008;29(2):155-92.

Kinane DF, Hart TC. Genes and gene polymorphisms associated with periodontal disease. Crit Rev Oral Biol Med 2003;14(6):430-49.

Kouskoura T, Fragou N, Alexiou M, John N, Sommer L, Graf D, et al. The genetic basis of craniofacial and dental abnormalities. Schweiz Monatsschr Zahnmed. 2011;121(7-8):636-46.

Küchler EC, Tannure PN, Falagan-Lotsch P, Lopes TS, Granjeiro JM, Amorim LM. Buccal cells DNA extraction to obtain high quality human genomic DNA suitable for polymorphism genotyping by PCR-RFLP and Real-Time PCR. J Appl Oral Sci. 2012;20(4):467-71. 
Küchler EC, Tannure PN, Oliveira DS, Charone S, Nelson-Filho P, Silva RA, et al. Polymorphisms in genes involved in enamel development are associated with dental fluorosis. Arch Oral Biol. 2017;76:66-9.

Li Q, Li X, Zhang F, Chen F. The identification of a novel locus for mandibular prognathism in the Han Chinese population. J Dent Res. 2011;90(1):53-7.

Li Q, Zhang F, Li X, Chen F. Genome scan for locus involved in mandibular prognathism in pedigrees from China. PLoS One. 2010;5(9).

Lips A, Antunes LS, Antunes LA, Abreu JGB, Barreiros D, Oliveira DSB, et al. Genetic Polymorphisms in DEFB1 and miRNA202 Are Involved in Salivary Human $\beta$ Defensin 1 Levels and Caries Experience in Children. Caries Res. 2017;51(3):20915.

Liu F, van der Lijn F, Schurmann C, Zhu G, Chakravarty MM, Hysi PG, et al. A genome-wide association study identifies five loci influencing facial morphology in Europeans. PLoS Genet. 2012;8(9):e1002932.

Lundström A. Tooth size and occlusion in twins. A.B. Fahlcrantz, Stockholm, 1948.

Madeira, MC. Anatomia da face: bases anatomofuncionais para a prática odontológica. 8. ed.São Paulo: Sarvier; 2012.

Markovic MD. At the crossroads of oral facial genetics. Eur J Orthod. 1992;14(6):46981.

Mossey PA. The heritability of malocclusion: part 2. The influence of genetics in malocclusion. Br J Orthod. 1999;26(3):195-203.

Nakasima A, Ichinose M, Nakata S, Takahama Y. Hereditary factors in the craniofacial morphology of Angle's Class II and Class III malocclusions. Am J Orthod. 1982;82(2):150-6.

Nascimento MA, Sérvulo SS, Terada H, Oliveira DSB, Romano FL, Nelson-Filho P, Küchler EC. Associação entre polimorfismo P561 no GHR e no prognatismo mandibular: revisão sistemática e metánalise. $33^{\circ}$ Reunião Anual da Sociedade Brasileira de Pesquisa Odontológica, SBPqO; 7-10 de Setembro de 2016; Campinas, Sp. Anais. (Brazilian Oral Research. 2016; 30 (1 Suppl): 550.

Nieminen P, Morgan NV, Fenwick AL, Parmanen S, Veistinen L, Mikkola ML, et al. Inactivation of IL11 signaling causes craniosynostosis, delayed tooth eruption, and supernumerary teeth. Am J Hum Genet. 2011;89(1):67-81.

Pallares LF, Carbonetto P, Gopalakrishnan S, Parker CC, Ackert-Bicknell CL, Palmer AA, et al. Mapping of Craniofacial Traits in Outbred Mice Identifies Major Developmental Genes Involved in Shape Determination. PLoS Genet. 2015;11(11):e1005607.

Perillo L, Monsurrò A, Bonci E, Torella A, Mutarelli M, Nigro V. Genetic association of ARHGAP21 gene variant with mandibular prognathism. J Dent Res. 2015;94(4):56976. 
Proffit, Willian R; Fields, Henry W; Sarver, David M. Ortodontia contemporânea. $5^{\circ}$. Rio de Janeiro: ELSEVIER; 2012.

Ranade K, Chang MS, Ting CT, Pei D, Hsiao CF, Olivier M, et al. High-throughput genotyping with single nucleotide polymorphisms. Genome Res. 2001;11(7):1262-8.

Riedel, R. The relation of maxillary structures to cranium in malocclusion and in normal occlusion. Angle Orthod.July 1952; 22(3):142-45.

Risch NJ. Searching for genetic determinants in the new millennium. Nature. 2000;405(6788):847-56.

Roshandel D, Holliday KL, Pye SR, Ward KA, Boonen S, Vanderschueren D, et al. Influence of polymorphisms in the RANKL/RANK/OPG signaling pathway on volumetric bone mineral density and bone geometry at the forearm in men. Calcif Tissue Int. 2011;89(6):446-55.

Sasaki Y, Satoh K, Hayasaki H, Fukumoto S, Fujiwara T, Nonaka K. The P561T polymorphism of the growth hormone receptor gene has an inhibitory effect on mandibular growth in young children. Eur J Orthod. 2009;31(5):536-41.

Schulze C, Wiese W. [On the heredity of prognathism]. Fortschr Kieferorthop. 1965;26(2):213-29.

Suen LJ, Huang HM, Lee $\mathrm{HH}$. [A comparison of convenience sampling and purposive sampling]. Hu Li Za Zhi. 2014;61(3):105-11.

Suzuki, S. Studies on the so-called reverse occlusion. Journal of the Nihon University School of Dentrry.1961; 5: 51-58.

Tassopoulou-Fishell M, Deeley K, Harvey EM, Sciote J, Vieira AR. Genetic variation in myosin $1 \mathrm{H}$ contributes to mandibular prognathism. Am J Orthod Dentofacial Orthop. 2012;141(1):51-9.

Takashiba S, Naruishi K. Gene polymorphisms in periodontal health and disease. Periodontol 2000. 2006;40:94-106.

Tomoyasu Y, Yamaguchi T, Tajima A, Nakajima T, Inoue I, Maki K. Further evidence for an association between mandibular height and the growth hormone receptor gene in a Japanese population. Am J Orthod Dentofacial Orthop. 2009;136(4):536-41.

Tyagi AK, Prasad S, Majeed M, Aggarwal BB. Calebin A downregulates osteoclastogenesis through suppression of RANKL signalling. Arch Biochem Biophys. 2016;593:80-9.

Tweed CH. Clinical orthodontics. 2.St Louis: C. V. Mosby; 1966.

Xue F, Rabie AB, Luo G. Analysis of the association of COL2A1 and IGF-1 with mandibular prognathism in a Chinese population. Orthod Craniofac Res. 2014;17(3):144-9. 
Xue F, Wong R, Rabie AB. Identification of SNP markers on 1p36 and association analysis of EPB41 with mandibular prognathism in a Chinese population. Arch Oral Biol. 2010;55(11):867-72.

Zhao HY, Liu JM, Ning G, Zhao YJ, Zhang LZ, Sun LH, et al. The influence of Lys3Asn polymorphism in the osteoprotegerin gene on bone mineral density in Chinese postmenopausal women. Osteoporos Int. 2005;16(12):1519-24.

Zhang X, Dowd DR, Moore MC, Kranenburg TA, Meester-Smoor MA, Zwarthoff EC, et al. Meningioma 1 is required for appropriate osteoblast proliferation, motility, differentiation, and function. J Biol Chem. 2009;284(27):18174-83.

Zebrick B, Teeramongkolgul T, Nicot R, Horton MJ, Raoul G, Ferri J, et al. ACTN3 R577X genotypes associate with Class II and deepbite malocclusions. Am J Orthod Dentofacial Orthop. 2014;146(5):603-11.

Yamaguchi T, Park SB, Narita A, Maki K, Inoue I. Genome-wide linkage analysis of mandibular prognathism in Korean and Japanese patients. J Dent Res. 2005;84(3):255-9.

Yamaguchi T, Maki K, Shibasaki Y. Growth hormone receptor gene variant and mandibular height in the normal Japanese population. Am J Orthod Dentofacial Orthop. 2001;119(6):650-3.

Ye S. Polymorphism in matrix metalloproteinase gene promoters: implication in regulation of gene expression and susceptibility of various diseases. Matrix Biol. 2000;19(7):623-9.

Walsh MC, Choi Y. Biology of the RANKL-RANK-OPG System in Immunity, Bone, and Beyond. Front Immunol. 2014;5:511.

Wongdee K, Pandaranandaka J, Teerapornpuntakit J, Tudpor K, Thongbunchoo J, Thongon $\mathrm{N}$, et al. Osteoblasts express claudins and tight junction-associated proteins. Histochem Cell Biol. 2008;130(1):79-90. 

Anexo 



\section{Anexo A}

\section{AprovaçÃo do CoMITÊ dE ÉtICA}

\section{FACULDADE DE ODONTOLOGIA DE RIBEIRÃO PRETO/FORP/ USP}

\section{PARECER CONSUBSTANCIADO DO CEP}

\section{DADOS DO PROJETO DE PESQUISA}

Título da Pesquisa: Associação entre polimorfismos genéticos e alterações no perfil esquelético facial

Pesquisador: Mariele Andrade do Nascimento

Área Temática: Genética Humana:

(Trata-se de pesquisa envolvendo Genética Humana que não necessita de análise ética por parte da CONEP;);

Versão: 1

CAAE: 50765715.3 .0000 .5419

Instituição Proponente: Universidade de Sao Paulo

Patrocinador Principal: Financiamento Próprio

\section{DADOS DO PARECER}

Número do Parecer: 1.338.841

\section{Apresentação do Projeto:}

O projeto de pesquisa em questão pretende analisar a associação entre polimorfismos genéticos e alterações no padrão esquelético facial. Pacientes em tratamento ortodôntico na clínica de especialização de Ortodontia/Ortopedia da FORP-USP, com idade superior a oito anos, serão incluídos nesse estudo. Após assinatura do termo de consentimento livre e esclarecido pelos pacientes ou por seus responsáveis, a determinação do fenótipo do padrão esquelético facial será realizada por meio de teleradiografias, usando referências cefalométricas da mandíbula, da maxila e da base do crânio. Será realizada a coleta da saliva como fonte de material biológico para a extração de DNA. A genotipagem dos genes candidatos será realizada por PCR em tempo real/ Taqman. Os dados serão tabulados e analisados no programa Epi Info 7.0 e no software Plink. Todos os polimorfismos serão avaliados para verificar se estão em Equilíbrio de Hardy-Weinberg. Teste do quiquadrado ou exato de Fisher serão utilizados para avaliar se algum alelo ou genótipo está preferencialmente associado com algum padrão esquelético facial especifico. O nível de significância adotado será de $5 \%$.A temática proposta é original e importante para a área da saúde humana. O projeto está bem estruturado, com revisão bibliográfica adequada, pertinente ao tema e atualizada. Os pesquisadores apresentam formação

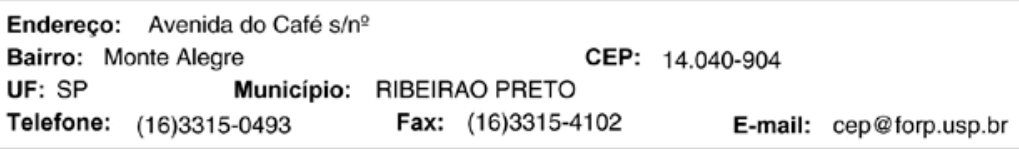




\section{FACULDADE DE ODONTOLOGIA DE RIBEIRÃO PRETO/ FORP/ USP}

Continuação do Parecer: 1.338 .841

acadêmica adequada para desenvolver o projeto

\section{Objetivo da Pesquisa:}

Hipótese:

Polimorfismos genéticos participam da etiologia dos diversos Padrões Esqueléticos Faciais.

Objetivo Primário:

Avaliar a associação entre polimorfismos genéticos e alterações fenotípicas nos Padrões Esqueléticos Faciais.

\section{Avaliação dos Riscos e Benefícios:}

Riscos:

O presente projeto apresenta riscos mínimos, relacionados com possíveis desconfortos como cuspir e ocupar um pouco o tempo do paciente.

Benefícios:

Os participantes da pesquisa não terão ganhos diretos com os resultados da mesma, mas terão como benefício orientação sobre técnica de higiene bucal, limpeza.

\section{Comentários e Considerações sobre a Pesquisa:}

O projeto está apresentado de forma correta, cumpre todas as normativas estabelecidas pelo CEP da FORP/USP e CONEP. Os pesquisadores são habilitados para execução do mesmo. Relevante para a área da saúde. Bem embasado cientificamente.

Considerações sobre os Termos de apresentação obrigatória:

Adequados.

\section{Recomendações:}

Aprovado.

Conclusões ou Pendências e Lista de Inadequações:

Aprovado.

Considerações Finais a critério do CEP:

Conforme deliberado na 186ª Reunião Ordinária do CEP, realizada em 25/11/2015.

Este parecer foi elaborado baseado nos documentos abaixo relacionados:

\begin{tabular}{|l|l|c|c|c|}
\hline \multicolumn{1}{|c|}{ Tipo Documento } & \multicolumn{1}{|c|}{ Arquivo } & Postagem & Autor & Situação \\
\hline Informações Básicas & PB_INFORMAÇÕES_BÁSICAS_DO_P & $04 / 11 / 2015$ & & Aceito \\
do Projeto & ROJETO_606659.pdf & $20: 14: 36$ & & \\
\hline
\end{tabular}

Endereço: Avenida do Café $\mathrm{s} / \mathrm{n}^{\circ}$

$\begin{array}{ll}\text { Bairro: } & \text { Monte Alegre } \\ \text { UF: SP } & \text { Município: }\end{array}$

Telefone: (16)3315-0493 Fax: (16)3315-4102 E-mail: cep@forp.usp.br 


\section{FACULDADE DE ODONTOLOGIA DE RIBEIRÃO PRETO/ FORP/ USP}

Continuação do Parecer: 1.338.841

\begin{tabular}{|c|c|c|c|c|}
\hline $\begin{array}{l}\text { Projeto Detalhado / } \\
\text { Brochura } \\
\text { Investigador }\end{array}$ & ProejtoDetalhado.docx & $\begin{array}{c}03 / 11 / 2015 \\
22: 12: 09\end{array}$ & $\begin{array}{l}\text { Mariele Andrade do } \\
\text { Nascimento }\end{array}$ & Aceito \\
\hline $\begin{array}{l}\text { TCLE / Termos de } \\
\text { Assentimento / } \\
\text { Justificativa de } \\
\text { Ausência }\end{array}$ & TCLE.doc & $\begin{array}{c}03 / 11 / 2015 \\
22: 06: 39\end{array}$ & $\begin{array}{l}\text { Mariele Andrade do } \\
\text { Nascimento }\end{array}$ & Aceito \\
\hline $\begin{array}{l}\text { TCLE / Termos de } \\
\text { Assentimento / } \\
\text { Justificativa de } \\
\text { Ausência }\end{array}$ & TCLEparamenores.doc & $\begin{array}{c}03 / 11 / 2015 \\
22: 04: 46\end{array}$ & $\begin{array}{l}\text { Mariele Andrade do } \\
\text { Nascimento }\end{array}$ & Aceito \\
\hline $\begin{array}{l}\text { TCLE / Termos de } \\
\text { Assentimento / } \\
\text { Justificativa de } \\
\text { Ausência } \\
\end{array}$ & TermodeAssentimento.doc & $\begin{array}{c}03 / 11 / 2015 \\
21: 56: 07\end{array}$ & $\begin{array}{l}\text { Mariele Andrade do } \\
\text { Nascimento }\end{array}$ & Aceito \\
\hline $\begin{array}{l}\text { Declaração de } \\
\text { Instituição e } \\
\text { Infraestrutura } \\
\end{array}$ & AutorizacaodainfraestruturaLab.pdf & $\begin{array}{c}28 / 10 / 2015 \\
15: 47: 59\end{array}$ & $\begin{array}{l}\text { Mariele Andrade do } \\
\text { Nascimento }\end{array}$ & Aceito \\
\hline Folha de Rosto & Fohaderosto.pdf & $\begin{array}{c}28 / 10 / 2015 \\
14: 30: 24 \\
\end{array}$ & $\begin{array}{l}\text { Mariele Andrade do } \\
\text { Nascimento }\end{array}$ & Aceito \\
\hline Cronograma & cronograma.docx & $\begin{array}{c}20 / 10 / 2015 \\
13: 17: 51 \\
\end{array}$ & $\begin{array}{l}\text { Mariele Andrade do } \\
\text { Nascimento }\end{array}$ & Aceito \\
\hline \begin{tabular}{|l|} 
Declaração de \\
Instituição e \\
Infraestrutura \\
\end{tabular} & AutorizacaodainfraestruturaClinica.pdf & $\begin{array}{c}20 / 10 / 2015 \\
12: 33: 27\end{array}$ & $\begin{array}{l}\text { Mariele Andrade do } \\
\text { Nascimento }\end{array}$ & Aceito \\
\hline
\end{tabular}

Situação do Parecer:

Aprovado

Necessita Apreciação da CONEP:

Não

RIBEIRAO PRETO, 26 de Novembro de 2015

\section{Assinado por: \\ Simone Cecilio Hallak Regalo \\ (Coordenador)}

Endereço: Avenida do Café $\mathrm{s} / \mathrm{n}^{\circ}$

Bairro: Monte Alegre

UF: SP

Municipio: RIBEIRAO PRETO

CEP: $14.040-904$

Telefone: (16)3315-0493

Fax: (16)3315-4102

E-mail: cep@forp.usp.br 